\title{
Considerações sobre o oriente em A cidade e as serras
}

\section{Daiane Cristina Pereira ${ }^{1}$}

RESUMO: No fim do século XIX , o Oriente se constituiu no imaginário europeu como espaço de exotismo e de referências sofisticadas. Pretendemos ver como A cidade e as serras, de Eça de Queirós, retoma tal perspectiva e a discute, mostrando como este espaço pode adquirir um caráter superficial e artificial, quando visto pelo olhar ocidental e pelo olhar do homem do fim desse século.

ABSTRACT: In the late nineteenth century, the Orient constitutes itself as a space of exotic and sophisticated references. We intend to analyze how the novel A cidade $e$ as serras, by Eça de Queirós, recovers this perspective and discusses it, showing how this space can acquire superficial and artificial aspects, when it's seen through the eyes of the Western man of the end of this century.

PALAVRAS-CHAVE: Eça de Queirós; Oriente; Literatura Portuguesa.

KEYWORDS: Eça de Queirós; Orient; Portuguese Literature.

Como podemos depreender do famoso livro de Edward W. Said, Orientalismo, o Oriente é um tema comum aos europeus de todas as épocas e de todos os países, incluindo Portugal (SAID, 2007). Durante o século XIX, com o aumento dos estudos referentes ao Oriente, assim como a progressão da política imperialista europeia, mais precisamente da Inglaterra e da França, este tema torna-se mais recorrente, tanto nos meios acadêmicos, quanto nos literários. Nesta época, são multiplicadas pelos ocidentais uma série de imagens que representarão o Oriente e o povo oriental, como nos diz Said no seguinte trecho: "O Oriente era praticamente uma invenção europeia e fora desde a Antiguidade um lugar de episódios romanescos, seres exóticos, lembranças, paisagens encantadas, experiências extraordinárias”. (SAID, 2007, p.27)

1 Mestranda do programa de Estudos Comparados de Literaturas de Língua Portuguesa da FFLCH-USP, desenvolvendo projeto cujo título é "A cidade $e$ as serras $e$ o fin-du-siècle”. E-mail: daiapereira@usp.br 
Este Oriente, inventado pelo Ocidente, ganha no fim do século XIX francês características peculiares. Os artistas, tomados pelo tédio e cansados do mundo moderno, procuraram uma evasão em mundos legendários e antigos. Além de recorrerem à tradição greco-romana, para executar tal evasão, os escritores recorreram ao Oriente, como espaço principalmente de exotismo e refinamento. Sob esta perspectiva, o Oriente aparecerá de diversas maneiras: será mostrado como elemento de refinamento e luxo, assim como caracterizará uma atitude cosmopolita, à maneira baudelairiana, sobre a qual nos fala Álvaro Manuel Machado (MACHADO,1983, p. 77) e será tido como local de evasão e restituição do espaço legendário, como se apresenta em Salammbô, de Flaubert. Além disso, ainda ligado à tentativa de evasão no mundo moderno, típica do pensamento decadente que se estabelece na Europa no fim de século. O Oriente, tido pelos ocidentais como berço de diversas religiões, coloca-se também como opção no sentido de possibilitar, através de sua mitologia, o acesso às novas formas de evasão. Dentro desta mesma perspectiva, as religiões orientais oferecem uma visão metafísica, diferente daquela da Igreja Católica, marcada por concepções materialistas e burguesas da vida, mediante as quais o homem do fim do século se sentia oprimido.

Eça de Queirós, como homem do seu tempo, não deixou de retratar o Oriente em seus textos. Apesar de abordar mais diretamente o tema em seus textos jornalísticos, o escritor português escreverá também um livro de viagem que se intitula $O$ Egito, além de dois romances, $O$ Mandarim e A Relíquia, que tem o Oriente como tema e como ambientação. Além disso, o romancista irá tratar do Oriente de maneira mais esparsa em diversos dos seus romances, entre eles A Cidade e as Serras, objeto deste trabalho.

O livro A Cidade e as Serras, lançado em 1901, foi concebido por Eça de Queirós no período de efervescência dos movimentos culturais que aconteceram no fim do século XIX, especialmente na França, bem como, do recrudescimento dos temas orientais dentro da literatura francesa, da qual, possivelmente, o romance faz alguns empréstimos. Dessa maneira, este trabalho pretende observar como as imagens do Oriente aparecem no romance queirosiano, mediante a perspectiva decadentista. Pretendemos analisar se o romance confirma ou se contrapõe às características que o Oriente adquiriu no imaginário francês do fim do século XIX além de observar como o estudo deste espaço nos permite entender melhor o romance. 


\section{O Oriente como decoração}

Como já referimos acima, o Oriente adquire em certos textos europeus a capacidade de rememorar um ambiente de luxo, refinamento e exotismo. O primeiro modo como observaremos as imagens do Oriente em A Cidade e as Serras será na forma de ambientação, ornamento, decoração, que reforçam com sua presença a necessidade do narrador, Zé Fernandes, de trazer ao personagem Jacinto e a algumas personagens que o cercam essa aura de refinamento. No entanto, a apresentação dessas mesmas imagens pelo narrador vão denunciando que essa aura apresenta algo de artificial, de superficial e não uma ligação verdadeira com o Oriente, ou uma tentativa de integração real com esse espaço.

No romance, por diversas vezes, o narrador faz referências a objetos orientais que fazem parte do dia-a-dia de Jacinto. Alude, por exemplo, a "damascos do Japão", "cigarros do Oriente" (QUEIRÓS, p.51), "tapete rico de Daguestan" (QUEIRÓS, p.115), banhos de "folhas de limonete da Índia" (QUEIRÓS, p.123), entre outras coisas, como elementos do Oriente que, além de revelarem parte do cotidiano de Jacinto, servem para mostrar também como o personagem circula em um ambiente rico e luxuoso. Através dos elementos do Oriente, o narrador apresenta Jacinto como um homem conhecedor deste espaço oriental e, desse modo, apresenta-o como cosmopolita.

No romance existem, no entanto, evidências que demonstram que, apesar de viver num ambiente luxuoso, exótico e refinado, Jacinto não retira qualquer prazer disso tudo, fazendo uso desse universo de maneira mecânica. Dessa forma, a atitude do homem refinado, que se utiliza dos elementos do Oriente para criar sobre si uma verdadeira aura de cosmopolitismo e mesmo de aristocratismo, torna-se superficial.

Lembremos, por exemplo, quando o narrador apresenta Jacinto tomando café de Moka (região portuária do Iêmen, exportadora de café no século XIX). Isto acontece duas vezes no romance: na primeira vez, José Fernandes diz que Jacinto encomenda o café ao seu feitor em Dedjah e manda fazê-lo à maneira turca; na segunda vez, o narrador diz que quem envia o café a Jacinto são os emires do deserto. Como podemos ver, há uma necessidade de mostrar ao leitor que o produto vem do Oriente e que Jacinto tem o poder de mandar buscá-lo. No entanto, na segunda vez em que a personagem aparece tomando café, o narrador deixa transparecer que esse café não satisfaz a Jacinto. Diz o narrador: "Ao lado pousava a chávena de Saxe, cheio desse café de Moka enviado pelos emires do deserto, que não o contenta nunca, nem pela força, 
nem pelo aroma" (QUEIRÓS, p.163). Dessa forma, podemos dizer que o narrador denuncia nesse trecho, além de certo esnobismo no comportamento de Jacinto, já que manda buscar café ao Oriente e nem assim se satisfaz. Parece que ele toma o café de Moka para demonstrar seu poder, apenas para afirmar seu refinamento e sua atitude cosmopolita. Assim, tomar o café de Moka não traz prazer à personagem, o que torna esta atitude artificial, já que todo o empenho para se ter um café de qualidade só se justificaria pelo prazer que bebida tão especial poderia proporcionar.

Outro momento interessante do texto, que se refere ao Oriente, é quando o narrador descreve os hábitos higiênicos de Jacinto. Vejamos o trecho abaixo para refletir mais detidamente como o Oriente, na vida cotidiana de Jacinto, mais uma vez apresenta, além do caráter refinado e exótico, típico do fim do século XIX francês, o sentimento de desprazer, de artificialidade, que torna a atitude de Jacinto muito superficial e livresca:

No 202, todas as manhãs, às nove horas, depois do meu chocolate e ainda em chinelas, penetrava no quarto de Jacinto. Encontrava o meu amigo banhado, barbeado, friccionado, envolto num roupão branco de pelo de cabra do Tibete, diante da sua mesa de toilette, toda de cristal (pôr causa dos micróbios) e atulhada com esses utensílios de tartaruga, marfim, prata, aço e madrepérola que o homem do século XIX necessita para não desfear o conjunto suntuário da Civilização e manter nela o seu Tipo. As escovas sobretudo renovavam, cada dia, o meu regalo e o meu espanto - porque as havia largas como a roda maciça dum carro sabino; estreitas e mais recurvas que o alfanje dum mouro; côncavas, em forma de telha aldeã; pontiagudas, em feitio de folha de hera; rijas que nem cerdas de javali; macias que nem penugem de rola! De todas, fielmente, como amo que não desdenha nenhum servo, se utilizava o meu Jacinto. E assim, em face ao espelho emoldurado de folhedos de prata, permanecia este Príncipe passando pelos sobre o seu pelo durante catorze minutos.(QUEIRÓS, p.59)

Como podemos observar, Jacinto utiliza-se de um número sem fim de objetos para sua toilette. Usa um roupão do Tibete e escovas que apresentam aspectos "orientais". A imagem toda do material com o qual são feitas as escovas e sua mesa de higiene remete para o Oriente, tendo em vista o olhar ocidental sobre este espaço. Entretanto, devemos ter em mente que, com exceção do roupão tibetano, os utensílios de higiene de Jacinto não são verdadeiramente orientais: quem os descreve, de maneira com que os percebamos assim, é o narrador Zé Fernandes. Podemos interpretar tal atitude do narrador de duas formas diferentes. Assim como Jacinto, Zé Fernandes deseja demonstrar que conhece o Oriente e é capaz de fazer uso do vocabulário que se refere a esse espaço geográfico, trazendo a si mesmo um caráter refinado. Essa hipótese se 
confirma em outros momentos do romance, como por exemplo, no momento em que ele descreve a sala de recepção de Madame d'Oriol, como algo que lembrava a ele o “Oriente e um Harém” (QUEIRÓS, p. 153), ou ainda quando descreve o romancista psicológico com “um deus índio” (cf . QUEIRÓS, 2012, . 92).

A segunda hipótese nos permite dizer que, além de demonstrar seu conhecimento do Oriente, o narrador pretende acentuar o caráter desprazeroso e artificial da atitude de Jacinto, através da carga negativa que atribui às palavras que usa para descrever os objetos. A descrição do roupão do Tibete não se reveste de caráter nem positivo nem negativo, no entanto a descrição das escovas como "estreitas e mais recurvas que o alfanje dum mouro", reforça a rudeza do objeto que machuca, já que além do alfanje ser um objeto cortante, a palavra "mouro" reporta-se ao tradicional inimigo do Ocidente e a seu estereótipo de indivíduo violento. Essa ideia de desprazer ainda é reforçada no final do trecho, quando Zé Fernandes demonstra o caráter mecânico da atividade de Jacinto: passa a escova em seus cabelos por quatorze minutos. As imagens às quais recorre o narrador, ao mesmo tempo em que refletem refinamento e luxo, servem também para demonstrar o desprazer que tais atividades causam a Jacinto, pois trazem em seu campo semântico referências à violência e à dor, como por exemplo, quando o narrador coloca que as cerdas das escovas são "pontiagudas" ou "rijas", que parecem machucar a pele de Jacinto.

Desse modo, podemos dizer que, no romance, as referências a elementos orientais se apresentam geralmente como "decorativas", sendo representativas de um ambiente refinado e luxuoso, tanto por parte do protagonista, como por parte do narrador, estando ali para demonstrar o poder de Jacinto em sua atitude cosmopolita e refinada, assim como o desprazer que essa mesma vida lhe inspira. Aproximar-se do requinte do Oriente, neste caso, reveste-se de um caráter artificial e desprazeroso, ao contrário do que se deveria supor.

\section{O Oriente como espaço da religião}

Com o crescente interesse pelo Oriente, cresce também o interesse pelas religiões que vêm desse espaço geográfico. No fim do século XIX, o homem cansado do mundo materialista e injusto que se lhe impõe, torna-se céptico e busca atrelar suas convicções a diferentes formas de pensamento e diferentes formas de religião, tendo o 
Oriente como fonte de muitas delas. Ao tratar de Ernest Renan (1823-1892), Pierrot observa que:

L'éclectisme religieux de Renan et sés études des civilisations sémitiques, l'énorme brassage des croyances et des mythes que comportait, nous l'avons vu, la Tentation de Saint Antoine, jouaient aussi dans le même sens, pour élargir considérablement les curiosités et conaissances des milieux littéraires au-delà de la tradition proprement occidentale et mettre au jour, avec l'épanoussement de l'histoire de l'époque positiviste, de nouveaux ensembles mythiques appartenant à des civilisations élognées dans le temps ou dans l'espace. (PIERROT, 1977, p, 238) ${ }^{2}$

Em A Cidade e as Serras temos uma representação muito especial de como as religiões de bases orientais possuem grande importância no século XIX e de como se colocam como opção para o homem do fim desse século.

Em vários momentos do romance, a questão da religião aparece, no entanto, há um muito especial que desejamos analisar. Trata-se da visita de Jacinto e Zé Fernandes à Basílica do Sacré-Coeur. Essa passagem é importante para o entendimento de como as religiões são trabalhadas dentro do romance, seja pela variedade de referências que apresentam, seja pela reflexão que se faz acerca delas.

Inicialmente, iremos comentar as referências que aparecem na parte em que José Fernandes e Jacinto encontram Maurício de Mayolle, quando estão descendo da Basílica para o apartemento do 202, nos Champs Elysée. Nesse trecho, Jacinto encontra o seu velho amigo Maurício e durante a conversa os dois passam a se referir a diversas correntes de pensamento e religião, entre elas, o renanismo, o hartmanismo, nietzschismo, etc. A referência à religião do Oriente aparece no final da conversa, pelas palavras de Maurício de Mayolle:

- Vim para Montmartre... Tenho aqui um amigo, um homem de gênio, que percorreu toda a Índia... Viveu com os Toddas, esteve nos mosteiros de Garma-Khian e de Dashi-Lumbo, e estudou com Gegen-Chutu no retiro santo de Urga... Gegen-Chutu foi a décima Sexta encarnação de Gautama, e era portanto um Bodhisattva... Trabalhamos, procuramos... Não são visões. Mas fatos, experiências bem antigas, que vêm talvez desde os tempos de Cristna...

2 O ecletismo religioso e Renan e seus estudos das civilizações semíticas, a enorme mistura de que continha, nós a vimos, a Tentation de Saint Antoine, jogam, também no mesmo sentido, por alargar consideravelmente as curiosidades e conhecimentos dos meios literários além da tradição propriamente ocidental e descobrir, com a eclosão da história da época positivista, novos conjuntos míticos que pertenciam a civilizações distantes no tempo e no espaço. (tradução do autor) 
Através destes nomes, que exalavam um perfume triste de vetustos ritos, arredara a cadeira. E de pé, deixando cair sobre a mesa, distraidamente, para pagar o absinto, moedas de prata e moedas de cobre, murmurava com os olhos descansados em Jacinto, mas perdidos noutra visão:

- Por fim tudo se reduz ao supremo desenvolvimento da Vontade dentro da suprema pureza da Vida. É toda a ciência e força dos grandes mestres hindus... Mas a pureza absoluta da vida, eis a luta, eis o obstáculo! Não basta mesmo o Deserto, nem o bosque do mais velho templo no alto Tibete... Ainda assim, meu Jacinto, já obtivemos resultados bem estranhos. Sabes as experiências de Tyndall, com as chamas sensitivas... O pobre químico, para demonstrar as vibrações do som, tocou quase às portas da verdade esotérica. Mas quê! Homem de ciência, portanto homem de estupidez, ficou aquém, entre as suas placas e suas retortas! Nós fomos além. Verificamos as ondulações da Vontade! Diante de nós, pela expansão da energia do meu companheiro, e em cadência com o seu mandado, uma chama, a três metros, ondulou, rastejou, despediu línguas ardentes, lambeu uma alta parede, rugiu furiosa e negra, resplandeceu direita e silenciosa, e bruscamente abatida em cinza morreu! (QUEIRÓS, p.147-148, grifo nosso)

Todas as menções grifadas acima se referem ao hinduísmo. Como podemos observar, mesmo que superficialmente, Maurício de Mayolle segue os preceitos do hinduísmo, após ter professado uma série de crenças. No entanto, devemos nos perguntar de que modo isso acontece. A personagem nos dá vários vocábulos referentes ao hinduísmo, mas, se observarmos melhor, não conhece os lugares que cita, nem os elementos da religião hindu, mas os menciona a partir da experiência de um amigo. Podemos depreender, dessa estratégia, que há a intenção de assinalar que não há nenhum contato direto com a referida religião do Oriente, da qual, paradoxalmente, se fala com aparente intimidade.

Além disso, se observarmos a segunda parte da fala de Maurício, podemos constatar que ele fala de aspectos externos à religião. Ele não menciona a ética que rege a religião, nem qualquer aspecto ligado a sua doutrina. $\mathrm{O}$ que nos chama a atenção na parte destacada é que Maurício de Mayolle ressalta as experiências que a religião proporciona, isto é, a transformação da energia do corpo de seu companheiro em labaredas. Nesse trecho, evidencia-se o ritual, a exterioridade da religião. É impossível não lembrar aqui que Eça dizia que sem rituais não haveria mais religiões, como deixa registrado através das palavras de Fradique Mendes:

Meu bom amigo, uma Religião a que se elimine o Ritual desapareceporque as Religiões para os homens (com exceção dos raros Metafísicos, Moralistas e Místicos) não passa dum conjunto de ritos 
através dos quais cada povo procura estabelecer uma comunicação íntima com o seu Deus e obter dele favores. Este, só este, tem sido o fim de todos os cultos, desde o mais primitivo, do culto de Indra, ate ao culto recente do coração de Maria, que tanto o escandaliza na sua paróquia - oh incorrigível beato do idealismo! (QUEIRÓS, 1997, p.127)

Fica evidente que a personagem trata o problema religioso de forma muito genérica, tornando clara a crítica de Eça ao superficialismo com que estas religiões orientais são tomadas. É como se toda a busca do homem do fim do século se transformasse numa série de modismos. Podemos dizer que essa conclusão encontra-se expressa na fala de Jacinto: “- O desenvolvimento supremo da Vontade!... Teosofia, Budismo esotérico... Aspirações, decepções... Já experimentei... Uma maçada!" (QUEIRÓS, 2012, p.149). Além disso, o modo displicente como Maurício de Mayolle fala da religião, soltando as palavras do mesmo modo como deixa as moedas para o pagamento do absinto e, também, a maneira como toma o aspecto de um asceta e expressa um olhar visionário soam falsos ao leitor, corroborando com a artificialidade e a exterioridade que a religião aparentemente assume no romance. No romance, as doutrinas religiosas têm o mesmo tratamento que o café de Moka, se é que este não aparece com maior consistência.

Em contrapartida, chama-nos a atenção a fala de Zé Fernandes, num momento anterior, no mesmo capítulo, em que ele faz seu famoso discurso contra a cidade. Após ter explicado seu ponto de vista sobre o materialismo, a injustiça social, o consumismo, a exploração do trabalho e a desilusão que é a vida na cidade, o narrador coloca a Jacinto e ao leitor uma série de questões:

Para amolecer tão duro granito só uma doçura divina. Eis pois esperança da Terra novamente posta num Messias!... Um decerto desceu outrora dos grandes Céus: e, para mostrar bem que mandado trazia, penetrou mansamente no mundo pela porta de um curral. Mas a sua passagem entre os homens foi tão curta! Um meigo sermão numa montanha, ao fim de uma tarde meiga; uma repreensão moderada aos Fariseus que então redigiam o "Boulevard"; algumas vergastadas nos Efrains vendilhões; e logo, através da porta da Morte, a fuga radiosa para o Paraíso! Esse adorável filho de Deus teve demasiada pressa em recolher a casa de seu Pai! E os homens a quem ele incumbira a continuação da sua obra, envolvidos logo pelas influências dos Efrains, dos Trèves, da gente do "Boulevard", bem depressa esqueceram a lição da Montanha e do lago de Tiberíade - e eis que por seu turno revestem a púrpura, e são Bispos, e são Papas, e se aliam à opressão, e reinam com ela, e edificam a duração do seu reino sobre a miséria dos sem-pão e dos sem-lar! Assim tem de ser recomeçada a 
obra da Redenção. Jesus, ou Gautama, ou Crishna, ou outro desses filhos que Deus por vezes escolhe no seio de uma Virgem, nos quietos vergéis da Ásia, deverá novamente descer à terra de servidão. Virá ele, o desejado? Porventura já algum grave rei do Oriente despertou, e olhou a estrela, e tomou a mirra nas suas mãos reais, e montou pensativamente sobre o seu dromedário? Já por esses arredores da dura Cidade, de noite, enquanto Caifás e Madalena ceiam lagosta no Paillard, andou um Anjo, atento, num vôo lento, escolhendo um curral? Já de longe, sem moço que os tanja, na gostosa pressa de um divino encontro, vem trotando a vaca, trotando o burrinho? (QUEIRÓS, p. 141)

Como podemos observar no trecho acima, o narrador cita, além das referências bíblicas, como Messias, Jesus, a Virgem e as figuras de Caifás e Madalena, referências orientais, como Gautama e Crishna, figuras que se reportam, respectivamente, ao budismo e ao hinduísmo. Remete ainda ao "desejado", isto é, ao retorno de D. Sebastião, figura messiânica, esperada pelos portugueses para a redenção de seu povo, fazendo de tudo isso um conto da Carochinha.

Dessa forma, o autor mostra-nos a artificialidade da atitude de Maurício de Mayolle em contraposição à questão ética e à solução dos problemas sociais ligada à religião, que nos transmite a fala de Zé Fernandes. Acreditamos que ao fazê-lo o autor demonstra que a atitude do homem do fim do século se liga ao aspecto mais superficial, mais ritual da religião, tratando-a como se fosse modismo, vindo dos novos estudos sobre o Oriente. Estes modismos também podem advir da posição cética do homem frente à vida. A busca por uma religião torna-se mais importante que os aspectos morais e éticos em si, fazendo dessa busca algo mais perverso do que o próprio materialismo, quando visto pela perspectiva de um crente.

Outro ponto a se colocar, é que, diferentemente do que diz Machado (MACHADO,1983, p.84), o Orientalismo de Eça de Queirós não é apenas exercício de estilo. Acreditamos que, quando o autor discute os problemas sociais a partir das falas de Zé Fernandes, coloca como alternativa uma associação entre alguns aspectos éticos do Budismo, Hinduísmo e Cristianismo. No entanto, a contraposição entre os dois trechos analisados mostra que ao transplantar tais religiões ao Ocidente, elas são contaminadas pela degenerescência ocidental e se revestem de um caráter apenas ritual. Além disso, os questionamentos de Zé Fernandes demonstram a angústia do homem moderno em encontrar bases éticas que assentem sua vivência, o que os força a decair em modismos, como acontece com Mayolle. 
Podemos, então, admitir que o autor coloca para o homem do fim do século XIX, representado por Jacinto, o problema ético do debate religioso, com suas referências ocidentais e orientais, condenando o seu tratamento superficial.

\section{Conclusão}

Outras questões poderiam ser discutidas sobre o Oriente em Eça de Queirós, como, por exemplo, a questão do preconceito, presente na cena em que Zé Fernandes é chamado de sale maure (mouro sujo) por um estudante francês. No entanto, nosso intuito aqui foi o de observar como o autor revisita as referências ao Oriente no romance A Cidade e as Serras conforme as perspectivas da ambientação e das doutrinas. A partir do que vimos acima, podemos dizer que o autor mostra através da atitude de Jacinto e da narração de Zé Fernandes quão artificial se tornam tais referências quando tratadas pelo europeu, seja pela necessidade de refinamento, seja para suprir uma necessidade metafísica.

Não há nenhuma evidência no livro que condene a aproximação entre Ocidente e Oriente, mas apenas críticas ao modo com que os europeus se aproximam do complexo e amplo universo que se convencionou designar de Oriente, isto é, uma apropriação sem reflexão, sem conhecimento de fato, ritualizada e sempre insatisfatória, já que é pautada pela lógica do modismo e do consumo.

\section{Referências Bibliográficas:}

MACHADO, Álvaro Manuel, O Mito do Oriente na Literatura Portuguesa. Lisboa: Instituto de Cultura e Língua Portuguesa, 1983.

PIERROT, Jean, L'imaginaire décadent (1880-1900). Paris, Presses Universitaires de France, 1977.

QUEIRÓS, Eça. A Cidade e as Serras. São Paulo, Ateliê: 2008.

QUEIROZ, Eça de. Obra completa. Rio de Janeiro: Nova Aguilar, 1997.

SAID, W. Edward. O Orientalismo: O oriente como invenção do Ocidente. São Paulo: Companhia das Letras, 2007. 